\title{
Fuzzy Logic Control of an Isothermal CSTR with Input Multiplicities
}

\author{
Ginuga Prabhaker Reddy ${ }^{1}$ Ballekallu Chinna Eranna ${ }^{2}$ \\ ${ }^{1}$ Dept. of Chemical Engineering Univ. College of Tech., Osmania University Hyderabad, India \\ ${ }^{2}$ Dept. of Chemical Engineering Univ. College of Tech., Osmania University Hyderabad, India
}

\begin{abstract}
In the present work, a Fuzzy logic controller is analyzed to a continuous stirred tank reactor (CSTR) carrying out series and parallel reaction: $A \rightarrow B \rightarrow C$ and $2 A \rightarrow D$ (Van de Vusse reaction) and exhibiting input multiplicities in the space velocity, on the product concentration (B). Continuous Stirred Tank Reactor which exhibits input multiplicities in space velocity on concentration of (B). i.e., two values of space velocity will give the same value of concentration. The present Fuzzy controller provides always the two values of space velocity for control action and by selecting the value nearer to the operating point, it is found to give stable and faster responses than linear PI controller. The Proportional Integral (PI) controller results in wash condition for a change over from initial lower input space velocity to higher input space velocity or vice versa.
\end{abstract}

Keywords:- Fuzzy logic control, CSTR, Input Multiplicities, Unstable response, lower input space velocity and higher input space velocity.

\section{INTRODUCTION}

For a Single Input and Single Output (SISO) process, more than one value of input variable producing same value of output is known as input multiplicity. As given in Figure 1. The two inputs $U_{1} \& U_{2}$ will produce the same output $Y$. Input multiplicities occur due to the competing effects in the processes. Dynamic and steady state behavior of the process with input multiplicity will remain distinct at different input values for the same output. Processes with multiple reactions, multi reactors or recycle structures are shown to exhibit input multiplicities as in [1] \& [2]. Conventional linear Proportional Integral (PI) controller will have control problems like instability, oscillatory and less economical as in [3] due to input multiplicities in the process. The inherent nonlinearity of the production of cyclopentenol process often renders control difficult as in [4].

In the last two decades, a new direction to control has gained considerable attention. This new approach to control is called 'Intelligent control'. The term 'intelligent control' addresses to more general control problems. It may refer to systems, which cannot be adequately described by differential equations framework. There are three basic approaches to intelligent control: knowledge-based experts systems, fuzzy logic and neural networks. The term 'conventional control' refers to theories and methods that are employed to control dynamic systems whose behavior is primarily described by differential and difference equations. Among these intelligent controllers, Fuzzy logic has become popular tool for control of dynamic process, demonstrating the ability of handling non linearity. Many fuzzy controllers are of the rule-based type where the controller's output response is described by a series of control rules as in [5], [6], [7] and [8].

In the present work, the design and evaluation of , unlike model based nonlinear controller, the less computationally involved fuzzy logic controller for an isothermal CSTR is proposed to overcome the control problems associated with conventional PI controller due to input multiplicities.

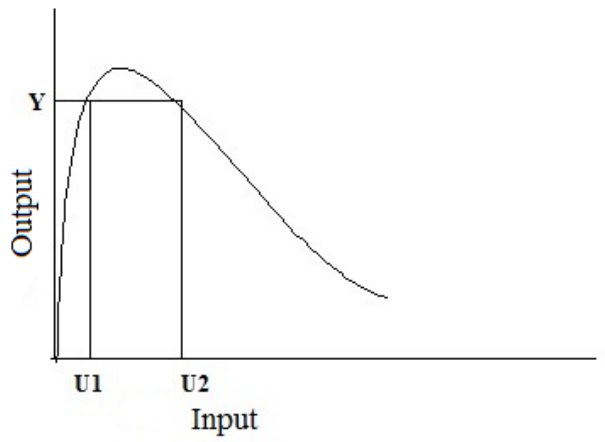

Figure 1 Steady state Behavior of Input Multiplicity process 


\section{DESCRIPTION OF A CSTR WITH INPUT MULTIPLICITIES}

We consider here a continuous stirred tank reactor (CSTR) with the following isothermal series and parallel reactions in as [9];

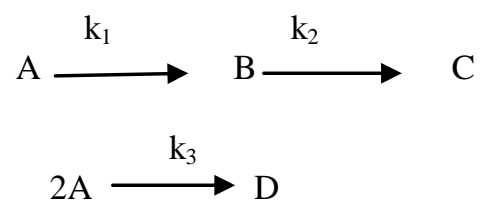

The product $\mathrm{B}$ is the desired one. The mass balance equations for $\mathrm{A}$ and $\mathrm{B}$ are given by [10]:

$$
\begin{gathered}
\mathrm{dx}_{1} / \mathrm{dt}=-\mathrm{k}_{1} * \mathrm{X}_{1}-\mathrm{k}_{3} * \mathrm{X}_{1}^{2}+\left(\mathrm{C}_{\mathrm{A}, 0}-\mathrm{X}_{1}\right) * \mathrm{u} \\
\mathrm{dX}_{2} / \mathrm{dt}=\mathrm{k}_{1} * \mathrm{X}_{1}-\mathrm{k}_{1} * \mathrm{X}_{2}+\mathrm{X}_{2} * \mathrm{u}
\end{gathered}
$$

Where,

$$
\mathrm{X}_{1}=\mathrm{C}_{\mathrm{A}}, \mathrm{X}_{2}=\mathrm{C}_{\mathrm{B}}, \mathrm{u}=\mathrm{F} / \mathrm{V}
$$

and $F$ is the flow rate $(1 / \mathrm{min}), C_{A}$ and $C_{B}$ are the concentration of $A$ and $B$ in the reactor $(\mathrm{mol} / \mathrm{l})$ and $C_{A, u}$ is the feed concentration of $\mathrm{A}(\mathrm{mol} / \mathrm{l})$. The parameters considered for the present work are given by $\mathrm{k}_{1}=0.8333$ $\left(\mathrm{min}^{-1}\right), \mathrm{k}_{2}=1.6667\left(\mathrm{~min}^{-1}\right), \mathrm{k}_{3}=0.16667\left(\mathrm{~mol}^{-1} * \mathrm{~min}^{-1}\right), \mathrm{C}_{\mathrm{A}, 0}=10(\mathrm{~mol} / \mathrm{l})$. The values of $\mathrm{X}_{2}$ vs $\mathrm{u}_{\mathrm{s}}$ is shown in Figure 2 Shows steady state input multiplicities in $\mathrm{u}_{\mathrm{s}}$ on the product concentration $\left(\mathrm{X}_{2, \mathrm{~s}}\right)$. That is two same values of $\mathrm{X}_{2, \mathrm{~s}}$ for example, $\mathrm{X}_{2}=1.117$ can be obtained at us $=0.5714$ and also at us=2.8746. The gain is +0.5848 at $\mathrm{u}=$ $0.5714 \mathrm{~min}^{-1}$ where as the gain is -0.1208 at $\mathrm{u}=2.8746 \mathrm{~min}^{-1}$. The conventional PI controller designed for lower $\mathrm{u}=0.5714$ will become unstable at higher $\mathrm{u}=2.8746$ due to negative sign of the process gain.

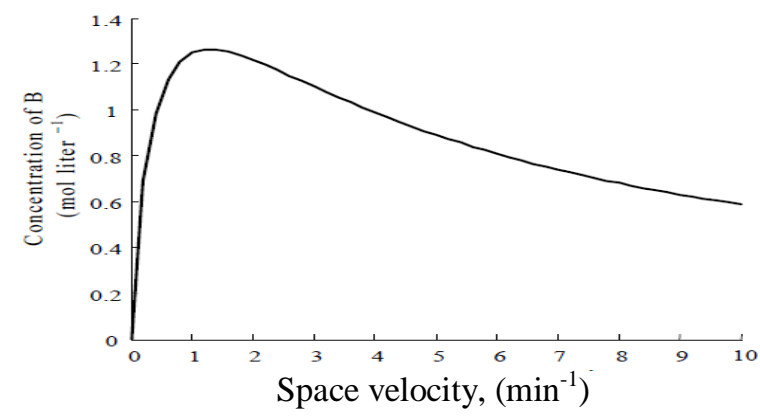

Figure 2 Steady state response space velocity of CSTR

\section{DESIGN OF A FUZZY LOGIC CONTROLLER (FLC)}

In the fuzzification step, the Concentration and concentration rate are selected as input variables. Universes of discourse of these input variables are divided into three fuzzy sets and they are linguistically called as HIGH, LOW and OK as shown in the Figures. $3 \& 4$. The Gaussian membership functions with the appropriate ranges have been used for these fuzzy sets. The lower and higher values of the space velocity ( $u$ ) have been selected as Fuzzy output variables.

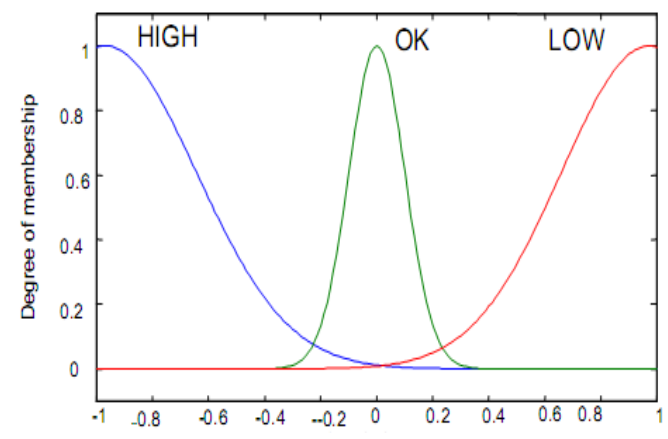

Figure 3 Fuzzy sets of concentration 


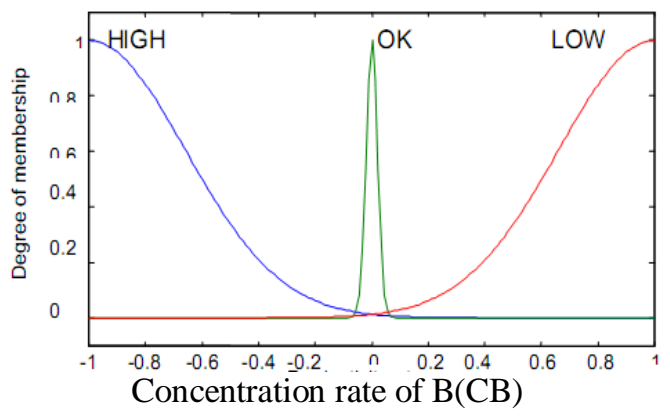

Figure 4.Fuzzy sets of concentration rate

Like input variables the universe of discourse of the output variables is divided into three fuzzy sets with linguistic names INCREASE, DECREASE, and NORMAL as shown in the Figures.5 \&.6

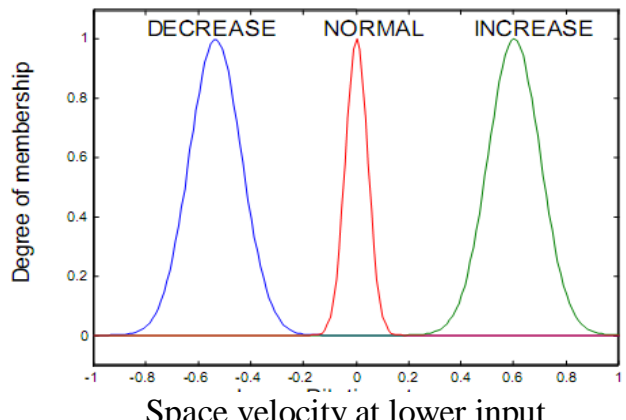

Figure 5. Fuzzy sets of Space velocity at lower input

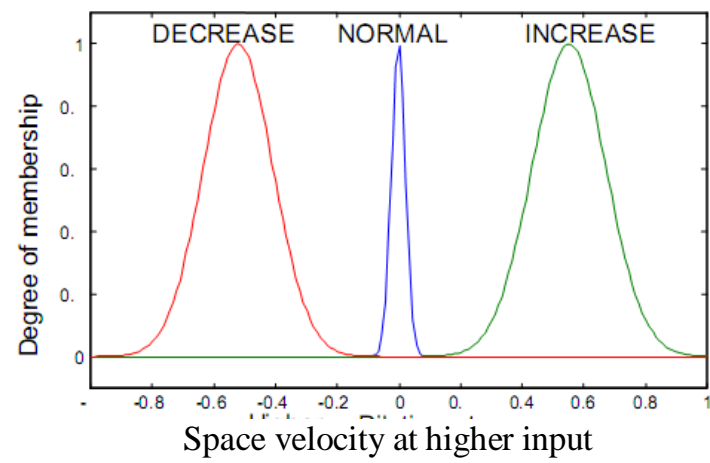

Figure 6. Fuzzy sets of Space velocity at higher input

In the rule base, the rules are selected to generate the control action at lower and higher values of Space velocity $(\mathrm{u})$. The rule base takes into account the opposite behavior at both the input values. i.e. process gain is positive at lower input value and it is negative at higher input value. The six rules are:

(1) If(concentration is HIGH) then (lower_Space velocity is DECREASE) (higher_ Space velocity is INCREASE)

(2) If (concentration is LOW) then (lower_Space velocity is INCREASE)(higher_ Space velocity is DECREASE)

(3) If (concentration is OK) then (lower_Space velocity is NORMAL)(higher_Space velocity is NORMAL)

(4) If (concentration is OK) and (Concentra--tion is HIGH) then (Lower_Space velocity is DECREASE) (higher_ Space velocity is INCREASE)

(5) If (concentration is OK) and (space velocity is LOW) then (lower_ Space velocity is INCREASE) (higher_Space velocity is DECREASE)

(6) If (concentration of $\left(\mathrm{C}_{\mathrm{B}}\right)$ is $\left.\mathrm{OK}\right)$ and (space velocity is OK)then(lower_SpacevelocityisNORMAL)(higher_Space velocity is NORMAL)

The centroid method has been used to obtain the crisp value in the Space velocity. The fuzzy controller always provides two crisp values i.e. one is at lower value $(\mathrm{u}=0.5714 \mathrm{Min}-1)$ and the other is at higher value $(\mathrm{u}=$ 
2.8744 Min-1) in dilution rates for control action and the value, which is nearer to the operating value between these two, is to be selected for the implementation.

\section{SIMULATION RESULTS AND DISCUSSION}

The performance of proposed fuzzy logic controller and conventional PI controller to the Continuous stirrer tank reactor with input multiplicities in space velocity is evaluated using the closed loop block diagrams as shown in Figurers $7 \&$ 8. These block diagram are developed using MATLAB version 6.1 and its associated SIMULINK and FUZZY LOGIC tool boxes. The scaling factors (gains): Gain=05, Gain1=10, Gain2=0.0065, Gain3=0.0065 for the fuzzy logic controller have obtained by trial and error method from simulation studies. The parameters of conventional PI controller used in the simulation studies are, $\mathrm{K}_{\mathrm{c}}=1.25, \tau_{\mathrm{I}}=0.008 \mathrm{~min}^{-1}$ as in [11]

At lower Space velocity, the regulatory response in concentration of fuzzy logic and conventional PI is shown in Figur 9 for a step change in feed concentration $\left(C_{\mathrm{AO}}\right)$ from 10 to $9 \mathrm{~mol} / \mathrm{l}$. This result shows that the

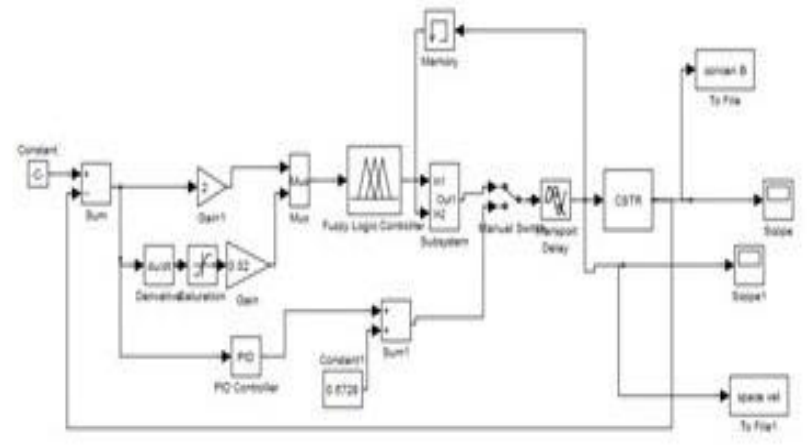

Figure 7. Block diagram for fuzzy logic controller \& conventional PI controller

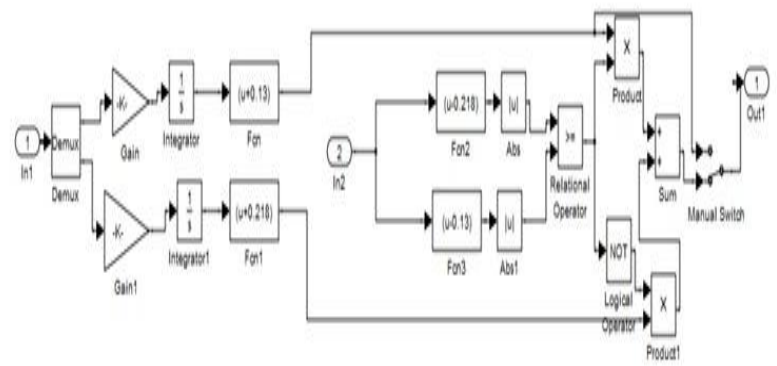

Figure 8. Block diagram for subsystem of fuzzy logic controller shown in Figur 7

faster than that of the linear PI. Present controller has maximum deviation of less than $2 \%$ where as PI controller has a lager deviation of about $6 \%$. Fuzzy logic controller has lower settling time than the PI controller. The corresponding control actions are smooth and they are shown in Fig. 10

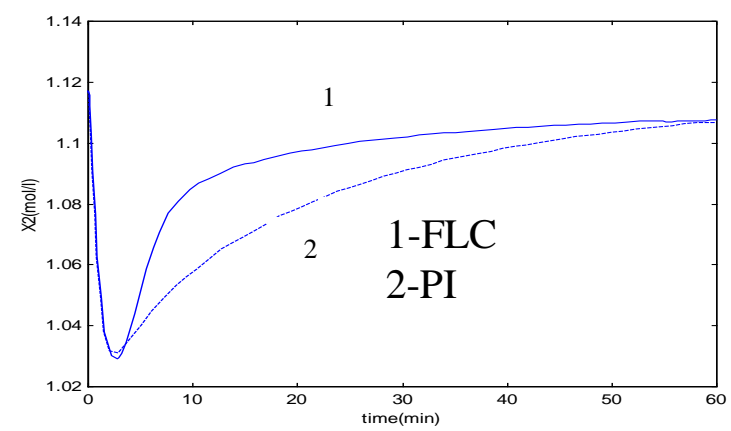

Figure 9. Closed loop response in $\mathrm{C}_{\mathrm{B}}$ for a disturbance change in $\mathrm{C}_{\mathrm{Ao}}$ from 10 to $9 \mathrm{~mol} / \mathrm{l}$ at lower input. 


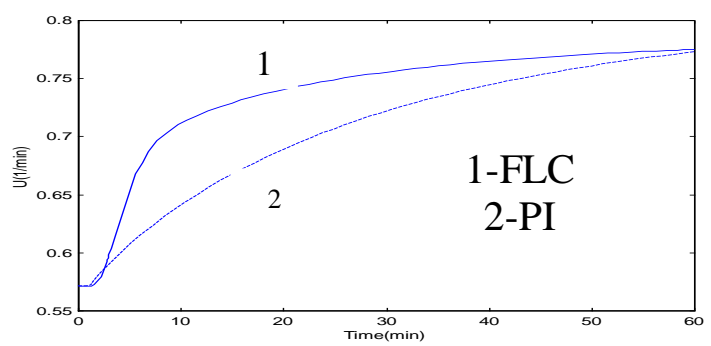

Figure 10. Space velocity versus time for the response shown in Figure 9.

And, at higher Space velocity, the regulatory response of fuzzy logic and conventional PI controller have been studied and shown in Figure 11 for a step change in feed concentration from 10 to $11 \mathrm{~mol} / \mathrm{l}$. This shows that the response of the fuzzy logic controller is smooth and reaches the set point very fast. And, whereas conventional PI controller results unstable. The control actions in space velocity are shown in Fig. 14

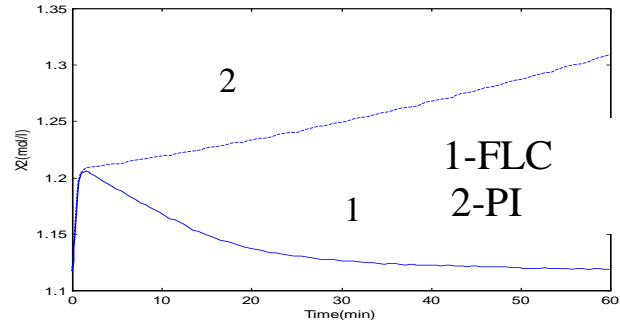

Figure 11.Closed loop response in $\mathrm{C}_{\mathrm{B}}$ for a disturbance change in $\mathrm{C}_{\mathrm{AO}}$ from 10 to $11 \mathrm{~mol} / \mathrm{l}$ at higher input.

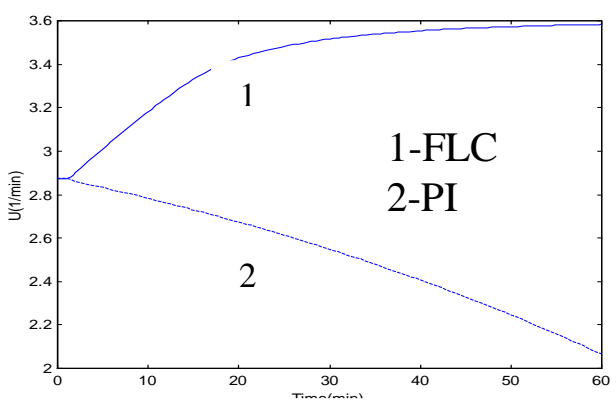

Figure 12. Space velocity versus time for the response shown in fig. 11 .

\section{CONCLUSION}

For a continuous stirrer tank reactor with input multiplicities in space velocity, the performance of present fuzzy logic controller at higher and lower input rates is found to much superior to that of the conventional PI controller at lower dilution rate. At higher dilution rate, the fuzzy logic controller gives satisfactory responses, whereas the linear PI controller (designed at higher space velocity) will give unstable responses. Thus, the present fuzzy logic controller is superior to linear PI controller at higher and lower space velocity and can overcome the control problems due to the input multiplicities.

\section{REFERENCES}

[1] L.B. Koppel “ Input multiplicities in nonlinear multivariable control systems " AIChE Journal.,Vol. 28 pp935 -945,1982.

[2] L.B. Koppel,. "Input multiplicities in process control”, Chemical Engineering Education, pp58-63, \& 89-92, 1983.

[3] S.K.Dash, and L.B.Koppel, “ Sudden destabilization of controlled chemical Processes”, Chemical Engineering Communications, Vol.84, pp 129-157 1989.

[4] M.A. Henson and D.E.Seborg, “ Nonlinear control strategies for continuous fermentation ”, Chemical Engineering Science, Vol.47, No.4, pp 821-835, 1992.

[5] E.H.Mamdani, S.Assilian,. "An experiment in linguistic synthesis with a fuzzy logic controller International”, Journal of ManMachine Studies. Vol.7 pp1-13, 1975.

[6] J.Abonyi, R..Babuska, and M. Ayala Botto, F.L.Szeifert, and Nagy "Identification and control of nonlinear systems using fuzzy hammerstein models", Industrial \& Engineering chemistry Research.,Vol.39 pp4302-4314, 2002.

[7] M.Srinivas and M.Chidambaram, "Fuzzy logic control of an unstable bioreactor", Bioprocess Engineering. Vol.12 pp135-139, 1995.

[8] H.B.Verbruggen, and P.M.Bruijn, "Fuzzy control and conventional control, what is (and can be) the real contribution of Fuzzy systems", Fuzzy sets and Systems. Vol.90 pp151-160, 1975.

[9] Van de Vusse, "Plug flow type reactor versus Tank reactor", Chemical Engineering Science, Vol.16, pp 994-997, 1964.

[10] C.Kravaris and P. Daoutidis, " Nonlinear state feedback control second order non minimum nonlinear systems" Chemical Engineering Science, Vol.14, pp 439-498, 1990

M.Chidambaram and G.P.Reddy, "Nonlinear control of systems with input multiplicities", Computers and Chemical Engineering,, Vol.19 pp249-252, 1995. 